\title{
СИНТЕЗ И ИССЛЕДОВАНИЕ СТЕКЛООБРАЗОВАНИЯ В СИСТЕМЕ $\mathrm{AS}_{2} \mathrm{~S}_{3}$-ERS
}

\author{
Ильясли Теймур Мамед \\ Бакинский государственный университет, д.х.н., профессор, \\ заведуюший кафедрой «Общей и неорганической химии, Баку \\ Гасанова Дуния Талех \\ Бакинский государственный университет, \\ аспирантка кафедры «Общей и неорганической химии, Баку \\ Алиев Имир Ильяс \\ Институт Катализа и Неорганической Химии \\ им. М.Ф.Нагиева НАН Азербайджана, д.х.н., профессор, рук. лаб.
}

\begin{abstract}
Аннотация. Для определения области стеклообразования в системе $\mathrm{As}_{2} \mathrm{~S}_{3}-\mathrm{ErS}$ были синтезированы сплавы в диапазоне концентраций 0-30 моль. \% Методами физико-химического анализа дифференциально-термического (ДТА), рентгенофазового (РФА), микроструктурного (МСА) анализов, а также измерения микротвердости и плотности, определили площадь стекла и изучали их физико-химические свойства. В результате физикохимического анализа построена микродиаграмма системы $\mathrm{As}_{2} \mathrm{~S}_{3}-\mathrm{ErS}$ в области 0-30 моль. \% ErS. Установлено, что в системе $\mathrm{As}_{2} \mathrm{~S}_{3}-\mathrm{ErS}$ на основе $\mathrm{As}_{2} \mathrm{~S}_{3}$ при медленном охлаждении области стекла достигает 17 моль. \% ErS. Сплавы в диапазоне концентраций 20-30 моль. \% ErS представляют собой стекло-кристаллические. В системе при комнатной температуре твердые растворы на основе $\mathrm{As}_{2} \mathrm{~S}_{3}$ доходят до 2,5 моль. \% ErS, а на основе твердых растворов ErS практически не установлены.

Abstract. To determine the area of glass formation in the system $\mathrm{As}_{2} \mathrm{~S}_{3}$-ErS were synthesized alloys in the range of concentrations 0-30 mol. \% ErS. The methods of physico-chemical analysis of differential-thermal (DTA), X-ray phase (RFA), microstructural (MCA) analyzes, as well as the measurement of microhardness and density determined the area of the glass and studied them physico-chemical propertes. It is established that in the system $\mathrm{As}_{2} \mathrm{~S}_{3}-\mathrm{ErS}$ on the basis of $\mathrm{As}_{2} \mathrm{~S}_{3}$ during slow cooling the area of the glass reaches 17 mol. \% ErS. Alloys in the concentration range 20-30 mol. \% ErS are glass-crystalline. In the system at room temperature solid solutions on the basis of $\mathrm{As}_{2} \mathrm{~S}_{3}$ are distributed up to $2.5 \mathrm{~mol} . \%$ ErS, and on the basis of solid solutions ErS are practically not installed.
\end{abstract}

Ключевые слова: система, стекло-кристалл, микротвердость, плотность, сингония.

Keywords: system, glass-crystal, microhardness, density, syngony.

\section{ВВЕДЕНИЕ}

Несмотря на то, что стеклянные полупроводники - молодая область науки, в последние годы они привлекают внимание исследователей как материалы с широкой областью применения. В частности, халькогенидные соединения мышьяка и стеклообразные халькогенидные соединения на их основе используются в электронике как светочувствительные и люминесцентные материалы [1-9]. Халькогенидные волокна стеклообразного типа на основе $\mathrm{As}_{2} \mathrm{~S}_{3}$ и $\mathrm{As}_{2} \mathrm{Se}_{3}$, разработанные для светопропускания в среднем ИК-диапазоне, нашли применение в различных областях микроэлектроники [10-13]. Другой компонент системы $\mathrm{As}_{2} \mathrm{~S}_{3}-\mathrm{ErS}$ - сульфид редкоземельного элемента. Халькогениды редкоземельных элементов и сложные фазы на их основе являются светочувствительными, термоэлектрическими, магнитными и люминесцентными полупроводниковыми материалами [14-18].

Целью настоящей работы является определение области стеклообразования, а также изучение некоторых физико-химических свойств полученных фаз.

$\mathrm{As}_{2} \mathrm{~S}_{3}$ является стеклообразным полупроводником получается с открытом максимумом при $310^{\circ} \mathrm{C}$ и кристаллизуется в моноклинной сингонии с параметрами решетки: $\boldsymbol{a}=11,49 ; b=9,59 ; \mathrm{c}=4,25 \AA \dot{\AA}, \beta=90^{\circ} 27^{\prime}$ (пр. гр.

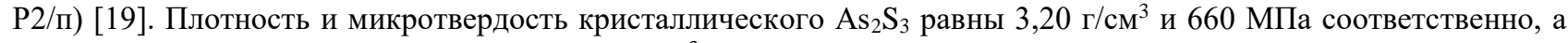

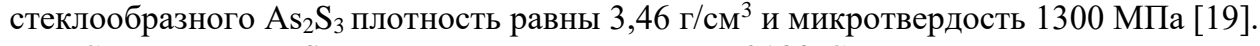

Соединение $\mathrm{ErS}$ плавится конгруэнтно при $2180^{\circ} \mathrm{C}$ и кристаллизуется типа $\mathrm{NaCl}$ в кубической сингонии с параметрами решетки: $a=5,424$ Á, пр.гр. Fm3m [20] .

\section{ЭКСПЕРИМЕНТАЛЬНАЯ ЧАСТЬ}

Для определения области стеклообразования в системе $\mathrm{As}_{2} \mathrm{~S}_{3}-\mathrm{ErS}$ синтезированы сплавы в пределах 0-30 моль. \% ErS. Компоненты $\mathrm{As}_{2} \mathrm{~S}_{3}$ и $\mathrm{ErS}$ были синтезированы из элементов следующей чистоты: мышьяк - 99,999\%, эрбий - 99,97\%, сера - марки ОСЧ.

Далее сплавы системы были синтезированы из компонентов $\mathrm{As}_{2} \mathrm{~S}_{3}$ и $\mathrm{ErS}$ в интервале температур $600-1100^{\circ} \mathrm{C}$. Полученные сплавы были подвергнуты термообработке при $300^{\circ} \mathrm{C}$ в течение 300 часов для гомогенизации. 
Физико-химический анализ: ДТА, РФА, МСА, а также измерением микротвердости и плотности сплавов системы $\mathrm{As}_{2} \mathrm{~S}_{3}$-ErS проводился как в стеклообразном, так и в кристаллическом состоянии.

Дифференциально-термический анализ сплавов системы проводили на приборе «ТЕРМОСКАН-2» со скоростью нагревания 5 град/мин.

Рентгенофазовый анализ проводили на рентгеновском приборе модели D2 PELASER с использованием СиК излучения, c Ni-фильтром. MCA сплавов системы исследовали с помощью металлографического микроскопа МИМ-8. При исследовании микроструктуры сплавов использовали травитель состава 10 мл $\mathrm{NaOH}+5$ мл $\mathrm{C}_{2} \mathrm{H}_{5} \mathrm{OH}=$ 1:1 время травления $15-20 \mathrm{c}$.

Микротвердость сплавов системы измеряли на микротвердомере ПМТ-3 при нагрузке 0,20 Н. Плотность сплавов системы определяли пикнометрическим методом, в качестве рабочей жидкости использовали толуол.

\section{РЕЗУЛЬТАТЫ И ИХ ОБСУЖДЕНИЕ}

Для определения области стеклообразования сплавов на основе $\mathrm{As}_{2} \mathrm{~S}_{3}$ во время взаимодействия с компонентами $\mathrm{ErS}$ и были исследованы методы физико-химического анализа и построена микродиаграмма (рис.1). Полученные образцы системы $\mathrm{As}_{2} \mathrm{~S}_{3}-\mathrm{ErS}$ в интервале концентраций 0-30 моль. \% ErS, компактные, темнокрасного цвета. Сплавы системы устойчивы к воде и воздуху. Они разлагаются теплой азотной кислотой $\left(\mathrm{HNO}_{3}\right)$ и щелочами $(\mathrm{NaOH}, \mathrm{KOH})$.

Физико-химические исследования сплавов системы $\mathrm{As}_{2} \mathrm{~S}_{3}$-ErS проводили до и после отжига. На термограммах кривых нагревания стеклообразных сплавов 0-30 моль. \% ErS до отжига имеются растянутые эффекты при $170-180^{\circ} \mathrm{C}$, которые совпадают с температурой размягчения $\mathrm{As}_{2} \mathrm{~S}_{3}$.

\section{Некоторые физико-химические свойства стекол системы $\mathrm{As}_{2} \mathrm{~S}_{3}-\mathrm{ErS}$}

Табл.1. (в стеклообразной форме)

\begin{tabular}{|c|c|c|c|c|c|c|c|}
\hline \multicolumn{2}{|c|}{ Составы, моль. \% } & \multicolumn{3}{|c|}{ Термические эффекты, ${ }^{\circ} \mathrm{C}$} & \multirow{2}{*}{ Микротвердость МПа } & \multirow{2}{*}{ 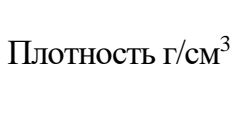 } & \multirow{2}{*}{ Результаты МСА } \\
\hline $\mathrm{AS}_{2} \mathrm{~S}_{3}$ & $\mathrm{E} \Gamma \mathrm{S}$ & $\mathrm{Tg}$ & Ткр. & Тпл. & & & \\
\hline 100 & 0 & 170 & 230 & 310 & 1350 & 3,20 & Стекло \\
\hline 97 & 3 & 170 & 230 & 310 & 1370 & 3,32 & - \\
\hline 95 & 5 & 175 & 245 & 305 & 1380 & 3,36 & - \\
\hline 93 & 7 & 185 & 250 & 300 & 1400 & 3,42 & - \\
\hline 90 & 10 & 190 & 260 & 280 & 1430 & 3,53 & - \\
\hline 85 & 15 & 190 & 260 & 260 & 1450 & 3,69 & - \\
\hline 80 & 20 & 210 & 265 & 420 & 1460 & 3,86 & - \\
\hline 75 & 25 & 220 & 270 & 550 & 1680 & 3.98 & Стекло, крист. \\
\hline 70 & 30 & 225 & 280 & 720 & 1680 & 4,18 & Стекло, крист. \\
\hline
\end{tabular}

После длительного отжига при при $250^{\circ} \mathrm{C}$ в течение 500 ч сплавов из области концентраций 0-30 моль. \% $\mathrm{ErS}$ на термограммах эффекты размягчения исчезают и остаются лишь эффекты, относящиеся к ликвидусу и солидусу.

Микроструктурный анализ литых сплавов показывает, что в интервале концентраций 0-20 моль. \% $\operatorname{ErS}$ они стеклообразны, а в сплавах, содержащих 20-30 моль. \% ErS, наблюдаются стеклокристаллические включения.

Табл. 2.

Состав сплавов системы $\mathrm{As}_{2} \mathrm{~S}_{3}$-ErS, термические эффекты, результаты измерений плотности или микротвердости (в кристаллической форме)

\begin{tabular}{|c|c|c|c|c|c|}
\hline \multicolumn{2}{|c|}{ Состав, моль. \% } & \multirow{2}{*}{$\begin{array}{c}\text { Термические эффекты, } \\
{ }^{\circ} \mathrm{C}\end{array}$} & \multirow{2}{*}{ 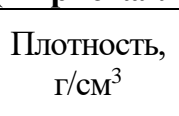 } & \multicolumn{2}{|c|}{ Микротвердость, МПа } \\
\hline $\mathrm{As}_{2} \mathrm{~S}_{3}$ & ErS & & & $\stackrel{r r}{\mathrm{P}=0,15 \mathrm{H}}$ & $\mathrm{P}=0,20 \mathrm{H}$ \\
\hline 100 & 0.0 & 310 & 3,46 & 700 & - \\
\hline 97 & 3,0 & 270,310 & 3,56 & 750 & - \\
\hline 95 & 5.0 & 265,305 & 3,64 & 780 & - \\
\hline 93 & 7,0 & 265,300 & 3,68 & 830 & - \\
\hline 90 & 10 & 265,280 & 3,71 & - & - \\
\hline 85 & 15 & 265 & 3,91 & Эвтект. & Эвтект. \\
\hline 80 & 20 & 265,420 & 4,07 & - & - \\
\hline 75 & 25 & 265,550 & 4,23 & & \\
\hline
\end{tabular}




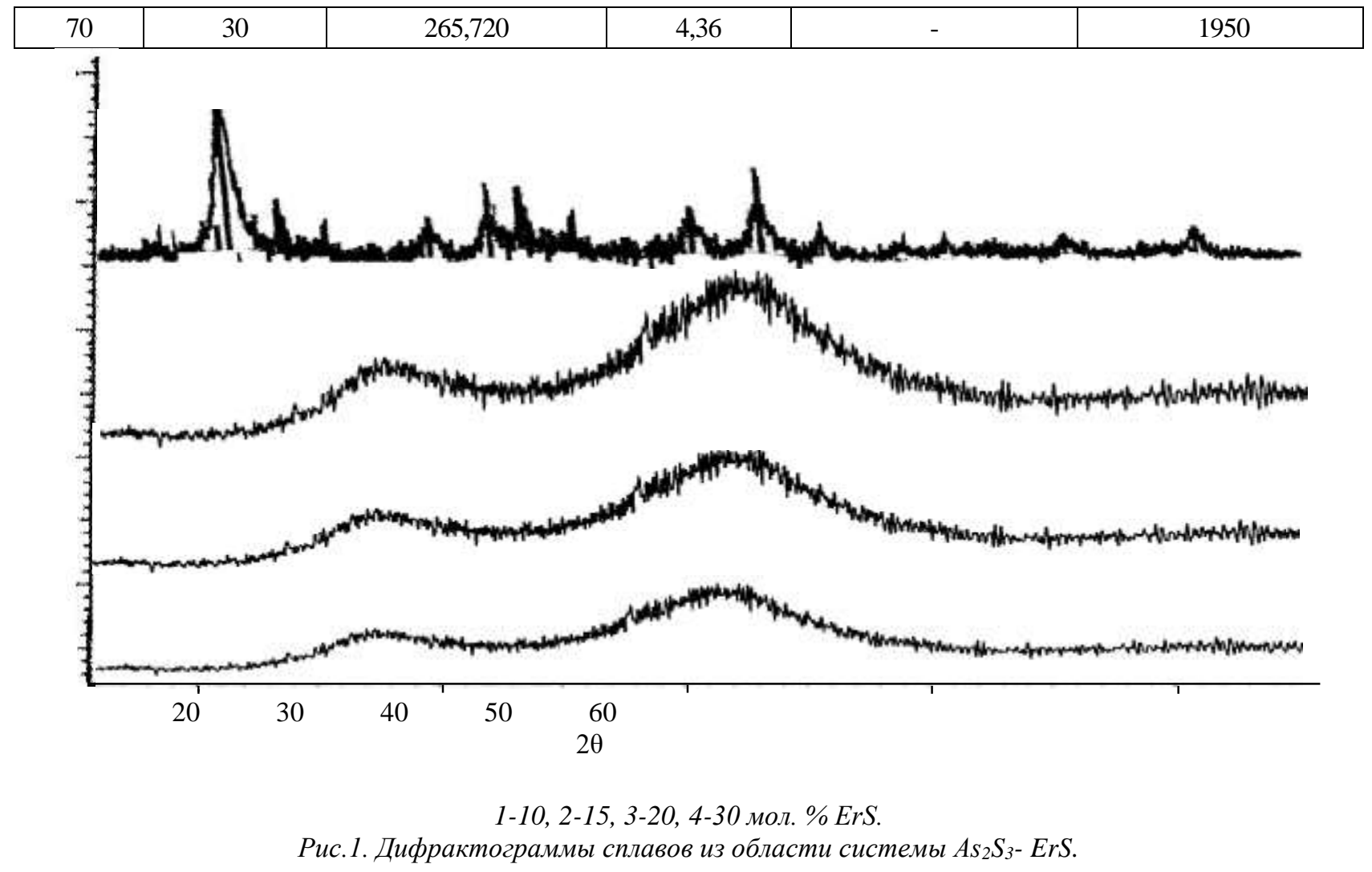

Некоторые физико-химические свойства сплавов из области стекол приведены в таблице 1. Как видно из таблицы 1, макроскопические параметры: температура размягчения (Tg), температуры кристаллизации и плавления, плотность и микротвердость сплавов системы $\mathrm{As}_{2} \mathrm{~S}_{3}$-ErS увеличиваются в зависимости от состава. Сплавы с составами 5, 10, 17 и 30 моль. \% ErS - это стекла, а сплав с составом 30 моль. \%. ErS относится к стеклокристаллической области.

Для сплавов из стеклообразной области системы $\mathrm{As}_{2} \mathrm{~S}_{3}$-ErS рентгенофазовый анализ проводился до и после отжига. Было установлено, что до отжига дифрактограммы сплавов из области концентраций 0-17 моль. \% ErS, дифракционные максимумы не наблюдаются (рис. 1). Сплавы в этой области были получены в виде стекла. Образцы в диапазоне 20-30 моль. \% ErS - стеклокристаллический. На дифрактограммах этих образцов наблюдаются слабые дифракционные максимумы (рис. 1).

В результате физико-химического анализа построена микродиаграмма системы $\mathrm{As}_{2} \mathrm{~S}_{3}$-ErS в области 0-30 моль. \% ErS (рис.2). 


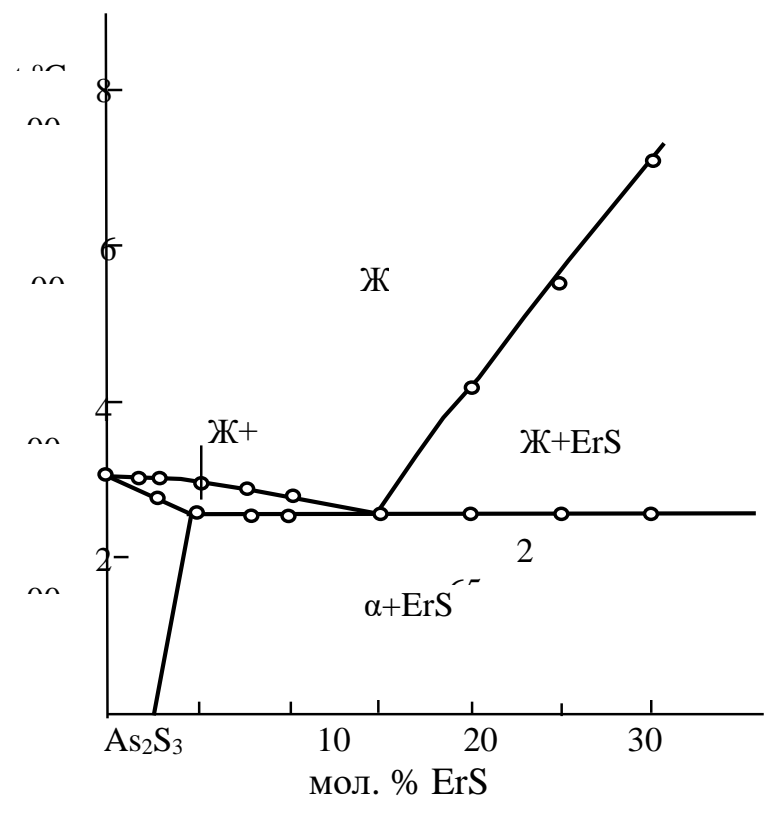

Рис.2. Микродиаграмма системы $\mathrm{As}_{2} \mathrm{~S}_{3}$-ErS.

Проведенный рентгенофазовый анализ полностью подтверждает результаты ДТА и МСА анализов. Некоторые физико-химические свойств сплавов из области стекол после отжига приведены в табл.2. Микротвердости сплавов системы $\mathrm{As}_{2} \mathrm{~S}_{3}-\mathrm{ErS}$ исследованы как в стекле, так и в кристаллической форме. Микротвердость сплавов из области 0-30 моль. \% ErS стекла находится в пределах МПа (1350-1380) (табл. 1). После кристаллизации этих же участков микротвердость изменяется в пределах (700-830) МПа (табл. 2).

\section{ЗАКЛЮЧЕНИЕ}

Методами физико-химического анализа: дифференциального термического (DTA), рентгенофазового (RFA), микроструктурного (MCA) анализов, а также путем измерения микротвердости, исследованы стеклообразование в системе $\mathrm{As}_{2} \mathrm{~S}_{3}-\mathrm{ErS}$ и изучены некоторые физико-химические свойства. Выявлено, что макроскопические параметры: температура размягчения ( $\mathrm{Tg}$ ), температуры кристаллизации и плавления, плотность и микротвердость сплавов системы $\mathrm{As}_{2} \mathrm{~S}_{3}$-ErS увеличиваются в зависимости от состава. Установлено, что в системе $\mathrm{As}_{2} \mathrm{~S}_{3}$-ErS на основе $\mathrm{As}_{2} \mathrm{~S}_{3}$ при медленном охлаждении области стеклообразования простираются до 17 моль. \% ErS. В интервале концентраций 20-30 моль. \% ErS сплавы является стеклокристаллическими. В системе при комнатной температуре на основе $\mathrm{A}_{22} \mathrm{~S}_{3}$ твердые растворы доходят до 2,5 моль \% $\mathrm{ErS}$, а на основе $\mathrm{ErS}$ твердые растворы практически не установлены.

\section{Список литературы}

1. Hari P., Cheneya C., Luepkea G., Singha S., Tolka N., Sanghera J.S., Aggarwal D.. Wavelength selective materials modification of bulk $\mathrm{As}_{2} \mathrm{~S}_{3}$ and $\mathrm{As}_{2} \mathrm{Se}_{3}$ by free electron laser irradiation // Journal of Non-Crystalline Solids. 2000. V. 270. P.265-268.

2. Dinesh Chandra SATI1, Rajendra KUMAR, Ram Mohan MEHRA Influence of Thickness Oil Optical Properties of a: $\mathrm{As}_{2} \mathrm{Se}_{3}$ Thin Films // Turk J Phys. 2006. V.30. P.519- 527.

3. Lovu M., Shutov S., Rebeja S., Colomeyco E., Popescu M. Effect of metal additives on photodarkening kinetics in amorphous $\mathrm{As}_{2} \mathrm{Se}_{3}$ films // Journal of Optoelectronics and Advanced Materials 2000. V. 2. Issue: 1. P 53-58.

4. Andriesh A.M., Verlan V. I.. Donor- and acceptor-like center revealing by Photoconduktivity of amorphous thin $\mathrm{As}_{2} \mathrm{Se}_{3}$ films // Journal of Optoelectronic and Advanced Materials. 2001. Vol. 3. No. 2, June. P. 455-458.

5. Hineva T., Petkova T., Popov C., Pektov P.. Reithmaier J. P., Funrmann-Lieker T., Axente E.. Sima F., Mihailescu C. N., Socol G., Mihailescu I. N. Optical study of thin $\left(\mathrm{As}_{2} \mathrm{Se}_{3}\right)_{1-\mathrm{x}}(\mathrm{AgI})_{\mathrm{x}}$ films // Journal of optoelektronics and Advanced Materials. 2007. V.9. No. 2. February. P. 326-329.

6. Seema Kandpal, Kushwaha R. P. S.. Photoacoustic spectroscopy of thin films of $\mathrm{As}_{2} \mathrm{~S}_{3}, \mathrm{As}_{2} \mathrm{Se}_{3}$ and $\mathrm{GeSe}_{2} / /$ Indian Academy of Sciences. PRAM ANA journal of physics. 2007. V. 69. No. 3. P. 481-484.

7. Бабаев А. А., Мурадов Р., Султанов С. Б., Асхабов А.М. Влияние условий получения на оптические и фотолюминесцентные свойства стеклообразных $\mathrm{AS}_{2} \mathrm{~S}_{3}$ // Неорган. материалы. 2008 . Т.44. №11. 
C. $1187-1201$.

8. lovu M., Shutov S., Rebeja S., Colomeyco E., Popescu M. Effect of metal additives on photo-darkenics in amorphous $\mathrm{As}_{2} \mathrm{Se}_{3}$ films // Journal of Optoelectronics and Advanced Materials. 2000. V.2. № 1. P. 53-58.

9. Seema Kandpal Kushwaha R. P. S. Photo acoustic spectroscopy of thin films of $\mathrm{As}_{2} \mathrm{~S}_{3}, \mathrm{As}_{2} \mathrm{Se}_{3}$ and $\mathrm{GeSe}_{2} / /$ Indian Academy of Sciences. PRAM ANA journal of physics. 2007. V. 69. No. 3. P. 481-484.

10. Moon J.A. and Schaafsma D.T., "Chalcogenide Fibers: An Overview of Selected Applications", Fiber and Integrated Optics, 2000. V.19. P. 201- 210.

11. Slusher R.E., Lenz G., Hodelin J., Sanghera J., Shaw L.B., Aggarwal I.D. Large Raman gain and nonlinear phase shifts in high-purity $\mathrm{As}_{2} \mathrm{Se}_{3}$ Chalcogenide fibers // J. Opt. Soc. Am. 2004. V. 21. P.1146-1155. 221106.

12. Jackson S.D., Anzueto-Sánchez G.;, Chalcogenide glass Raman fiber laser// Appl. Phys. Lett., 2006. V.88. P.

13. Fu L.B., Fuerbach A., Littler I.C.M., Eggleton B.J., Efficient optical pulse compression using Chalcogenide single-mode fibers // Appl. Phys. Lett. 2006. V.88. P.081116.

14. Fu L.B., Rochette M., Ta'eed V., Moss D., Eggleton B.J. Investigation of self-phase modulation based optical regeneration in single mode $\mathrm{As}_{2} \mathrm{Se}_{3}$ Chalcogenide glass fiber // Opt. Express. 2005. V.13. P. 7637-7641.

15. Никифоров В. Н., Морозкин А. В., Ирхин В. Ю. Термоэлектрические свойства редкоземельных сплавов // Физика металлов и материаловедение 2013. Т. 114. № 8. С.711-720.

16. Кудреватых Н. В., Волегов А. С. Магнетизм редкоземельных металлов и их интерметаллических соединений -Екатеринбург Издательство Уральского университета 2015. 196 с.

17. Wang Y., Zhu G., Xin Sh., Wang Q., Li Y., Wu Q., Wang Ch., Wang X., Ding X., Geng W. Recent development in rare earth doped phosphors for white light emitting diodes // Journal of Rare Earths. 2015. V. 33. N. 1. P. 1-12.

18. Caldiño U., M. Bettinelli, Ferrari M., Pasquini E., Pelli S., Speghini A., Righini G.C. Rare earth doped glasses for displays and light generation // Advances in Science and Technology. 2014. V. 90. P. 174-178.

19. Хворестенко А.С. Халькогениды мышьяка. Обзор из серии "Физические и химические свойства твердого тела". - М., 1972.93 с.

20. Диаграммы состояния двойных металлических систем. Справочник: В 3т: Т.3 // Под. Ред. Н.П. Лякишева. М.: Машиностроение. 1997.439 с. 